\title{
Population health surveillance using mobile telephone surveys in low- and middle-income countries: methodology and sample representativeness of a behavioural risk factor survey of live poultry exposure in Bangladesh
}

Isha Berry ( $\sim$ isha.berry@mail.utoronto.ca )

Dalla Lana School of Public Health, University of Toronto

Punam Mangtani

London School of Hygiene \& Tropical Medicine

Mahbubur Rahman

Institute of Epidemiology, Disease Control and Research

Iqbal Ansary Khan

Institute of Epidemiology, Disease Control and Research

\section{Sudipta Sarkar}

Institute of Epidemiology, Disease Control and Research

Tanzila Naureen

Institute of Epidemiology, Disease Control and Research

Amy L. Greer

University of Guelph

Shaun K. Morris

Hospital for Sick Children

\section{David N. Fisman}

Dalla Lana School of Public Health, University of Toronto

Meerjady Sabrina Flora

Institute of Epidemiology, Disease Control and Research

\section{Research Article}

Keywords: Mobile telephone survey, survey methodology, sampling, survey weighting, Bangladesh

Posted Date: February 16th, 2021

DOI: https://doi.org/10.21203/rs.3.rs-220907/v1

License: @ (i) This work is licensed under a Creative Commons Attribution 4.0 International License. Read Full License 


\section{Abstract}

\section{Background}

In low- and middle-income countries (LMICs), population-based health surveys are typically conducted using face-toface household interviews. However, telephone-based surveys are cheaper, faster, and can provide greater access to hard to reach or remote populations. The rapid growth in mobile telephone ownership in LMICs provides a unique opportunity to implement novel data collection methods for population health surveys. This study describes the methodology, development, and population representativeness of a mobile telephone survey measuring live poultry exposure in urban Bangladesh.

\section{Methods}

A population-based cross-sectional mobile telephone survey was conducted between September and November 2019 in North and South Dhaka City Corporations (DCC), Bangladesh to measure live poultry exposure using a stratified probability sampling design. Data were collected using a computer-assisted telephone interview (CATI) platform. Call operational data were summarized, and participant data were weighted by age, sex, and education to the 2011 census. Demographic distributions of the weighted sample were compared with external sources to assess population representativeness.

\section{Results}

A total of 5486 unique mobile telephone numbers were dialled, with 1047 respondents completing the survey. The survey had an overall response rate of $52.4 \%$ and a cooperation rate of $89.0 \%$. Initial results comparing the sociodemographic profile of the survey sample to the census population showed that mobile telephone sampling slightly underrepresented older individuals and overrepresented those with higher secondary education. After weighting, the demographic profile of the sample population was well matched to the latest DCC census population profile.

\section{Conclusions}

Probability-based mobile telephone survey sampling and data collection methods produced a population-representative sample with minimal adjustment in DCC, Bangladesh. Mobile telephone-based surveys can offer an efficient, economic, and robust way to conduct surveillance for population health outcomes, which has important implications for improving population health surveillance in LMICs.

\section{Background}

Representative population-based surveys are important for measuring health outcomes and behavioural risk factors at the national and sub-national level (1). These surveys can be used to provide key population health estimates, and if conducted at regular intervals can allow for monitoring health trends over time (1-3). In low- and middle-income countries (LMICs), population health surveys are typically conducted using face-to-face household-based interviews due to methodological challenges including lack of representative individual sampling frame (4). However, due to the high implementation costs and time required to conduct representative household surveys, they tend to only be conducted periodically (5). By contrast, higher income countries (HICs) have developed and employed annual telephone-based surveys, for instance to monitor behavioural risk factor trends $(6,7)$.

Telephone-based surveys are cheaper, faster, and can provide greater access to hard to reach or remote populations, particularly in the era of COVID-19, and hence are an appealing method by which to supplement or replace in-person 
household surveys in LMICs $(8,9)$. While sampling frames for probability-based telephone surveys have traditionally been limited to landlines in HICs, the growth of mobile telephone ownership and increasing number of mobile telephone-only households has led to the development of dual-frame sampling designs $(10,11)$. However, in LMICs growth in mobile telephone subscriptions has been exponential, with 22.9 subscriptions per 100 people in 2005 to 99.3 per 100 in 2020 (12). This rapid increase has led to cellular networks leapfrogging landline infrastructure, and mobile telephones becoming the primary mode of communication (13).

High levels of telephone ownership in LMICs provide a unique opportunity to implement novel data collection methods for population health surveys using mobile telephones as a primary sampling unit (13). However, there continue to be important methodological concerns regarding the use of mobile telephone surveys in producing population representative samples due to selection bias, coverage error, and low response rates (14). For example, the sociodemographic profiles of mobile telephone respondents have been shown to be different to those of face-to-face household survey respondents $(15,16)$. Recent systematic reviews identified only a few studies published using probability-based mobile telephone survey methods in LMICs and reported a lack of consensus on the best implementation approaches and analytic methods to overcome methodological challenges in these populations (17, 18).

In Bangladesh, where the mobile telephone penetration rate is over $87 \%$ (19), there is increasing use of telephone-based surveys for behavioural risk factor surveillance (20). In urban areas in particular, where the mobile penetration rate is even higher (21), these surveys have the potential to be especially useful for measuring population health outcomes. However, the population representativeness of these surveys has not been systematically evaluated and analytic methods such as poststratification adjustments have not been conducted (20). Therefore, the potential impacts of selection bias and coverage error on study findings and population estimates remain unknown.

This study aims to address these critical methodological gaps to support the use of probability-based mobile telephone survey methods for routine population health surveillance in LMICs. Here we describe the methodology and development of a mobile telephone survey measuring live poultry exposure in urban Bangladesh. Human-animal contact is a significant risk factor for the emergence of novel infectious diseases (22), and is therefore a key measure to capture in behavioral risk factor surveillance. Specifically, we provide an in-depth discussion of the methodology covering sample design, questionnaire development, data collection, and poststratification analytic methods, as well as call outcome results including response rates and population representativeness.

\section{Methods}

\section{Study Design \& Sampling}

A population-based cross-sectional telephone survey was conducted between September and November 2019 to recruit a representative sample of adult males and females in North and South Dhaka City Corporations (collectively known as DCC), in Dhaka, the capital of Bangladesh. The sampling frame was a list of mobile telephone numbers from each of Bangladesh's four mobile telephone operators (i.e., Grameenphone, Robi Axia, Banglalink, and Teletalk). Telephone numbers were restricted to those active in DCC, or if they could not be restricted to DCC, to those active in Dhaka District. Over 75\% of the population of Dhaka District resides in DCC (23). Telephone numbers were provided by each mobile telephone operator with the permission of the Bangladesh Telecommunication Regulatory Commission (BTRC).

A single stage stratified probability sampling design was used to select participants. Before selection, the telephone numbers were stratified by mobile operator and sampled in accordance with each operator's proportionate market share in order to maximize precision of the sample and ensure a representative distribution (Supplementary Table 1) (24). 
Within each operator list, simple random sampling was used to select telephone numbers. At the time of contact, each selected mobile telephone respondent was screened for eligibility and an equal number of male and female respondents were recruited to allow for robust sex-specific analyses. Individuals were eligible for inclusion if they were at least 18 years of age, current DCC residents, and had been residing in DCC for the past one year.

\section{Questionnaire Development}

The questionnaire was based on previous poultry exposure surveys conducted in urban China (25-28), but modified to the Bangladeshi context through discussions with an advisory panel $(n=12)$ consisting of local experts in survey design, mobile telephone surveys, and infectious diseases. Using a structured approach, the panel reviewed each survey question to assess the face and content validity of the items, as well as identify areas for potential adaptation or modification and item reduction or addition. Two rounds of review were conducted and any items that did not achieve group consensus (defined as $60 \%$ agreement) were modified and re-examined until consensus was reached. Key revisions from this step centered around prioritizing and selecting items that were deemed feasible and reliable to ask participants during a telephone interview. The questionnaire was translated into Bangla, and independently reviewed by two native-speakers with familiarity of the content matter to ensure comprehension and clarity.

The final survey instrument was comprised of five sections and captured information on exposure to live poultry through purchasing at live bird markets (LBMs) and food preparation, prevention practices, influenza-like illness (ILI), and socio-demographics. LBMs were defined as a collection of stalls or vendors where the general public could purchase live chickens, ducks, geese or any by-products of these in an unprocessed form (29). Specifically, questions covered the following topics: frequency of LBM visits and associated behaviours at markets, poultry processing practices during food preparation, uptake and adherence to hygiene practices and personal protective equipment (i.e., gloves, facemask, apron) during and after poultry exposure, self-reported ILI using a standard case definition (30), as well as household and individual-level socio-demographics. To minimize respondent burden while obtaining detailed information where appropriate, the survey used a significant amount of branching logic. The questionnaire underwent thorough review, and modifications were made as needed based on feedback from a pre-testing phase $(n=7)$ and a small-scale pilot $(n=41)$. The final, updated survey took approximately 10-15 minutes for respondents to complete.

\section{Data Collection \& Calling Procedure}

Both English and Bangla versions of the questionnaire were programmed into a customized computer assisted telephone interview (CATI) platform developed by the Institute of Epidemiology, Disease Control and Research (IEDCR) in Dhaka, Bangladesh. This platform managed both the sampling and data collection processes, including: complex form structure, automated repeat call attempts and interview rescheduling, automated strata monitoring on key variables (i.e., mobile telephone operator, sex of respondent) across interviewers, and pairing with a mobile telephone application to facilitate automated dialling of each selected telephone number. A team of four female data collectors were recruited to conduct telephone interviews, and data were entered into the CATI platform in real-time. Data collectors received four days of training on the survey methods and questionnaire topics before the start of piloting and data collection.

The survey was conducted between September and November 2019. In advance, a Bangla-language newspaper advertisement was placed in DCC's two most commonly circulated newspapers to inform the public that they may receive a call from IEDCR regarding a health survey, that telephone numbers were randomly selected with the permission of BTRC, and that participation was important for improving population health. Telephone calls were made every day (7 days a week) between 8am and 8pm (local time), except on Friday afternoons to account for local religious observances, to limit potential selection bias that could occur by only recruiting during weekdays and work hours. 
All telephone numbers were attempted up to four times to establish contact and conduct an interview with the respondent. Each unanswered call was automatically re-scheduled for a different time of day on a different day of the week over the following seven-day period. If the respondent was not reached after the maximum number of four call attempts, with at least one daytime and one evening call attempt, the telephone number was classified as 'no contact' and discontinued. At first successful contact, respondents were explained the purpose of the study, survey length, that participation was voluntary, and that all information they provided would be kept confidential. Eligibility was confirmed and consent for survey participation was obtained at the time of interview. When respondents were unable to complete the interview at the time of recruitment, the telephone interview was re-scheduled for a convenient time within the next seven days. Once an interview was completed, or if a respondent declined, refused or was ineligible, the telephone number was also discontinued from the call bank. An overview of the recruitment process is displayed in

\section{Supplementary Fig. 1. \\ Sample Size}

A total of 1040 complete interviews (520 males and 520 females) were required in order to detect an 8-9\% difference (65\% vs. $56 \%(26)$ ) in live poultry exposure between strata, with 95\% confidence and $80 \%$ power. The reason for explicitly stratifying by sex was to have sufficient statistical power to permit detailed exploration and identify notable differences in high-risk behaviours between males and females. This is important for ensuring appropriate and targeted risk-based implementation strategies.

\section{Data Analysis: Response, Weighting, and Representativeness}

Operational data for each telephone number dialled and the corresponding details for call outcome status were summarized. The overall and mobile operator-specific response rates were calculated according to the American Association for Public Opinion Research (AAPOR) Response Rate-3 definition, which includes those who were eligible and those estimated to be eligible in the denominator (31). The number estimated to be eligible was derived by assuming the proportion of eligible individuals amongst those contacted was the same as for those who were unable to be contacted or declined.

Demographic data for completed interviews were summarized, and the sample distributions were compared to the Dhaka City Corporation demographic profile of the 2011 census (23). To adjust for non-response and disproportionate stratified sampling by sex (i.e., oversampling of females as compared to the reference population), post-stratification weights were calculated by age, sex and education to align with the 2011 census. Participants with an invalid response to weighting variables (i.e., age, sex, education) were unable to be assigned a weight and therefore are not included in weighted analyses $(n=16)$. The demographic distribution of the weighted data was summarized and compared with external data sources to assess the representativeness of the sample population for other key demographic variables, including marital status and region. All analyses were conducted in Stata 16.1 (StataCorp, College Station, TX, USA).

\section{Results}

\section{Call Outcomes \&Response Rates}

Between September and November 2019, a total of 5486 unique telephone numbers were dialled. An overview of participant recruitment and outcome classification is presented in Fig. 1. Of all telephone numbers dialled, 2051 (37.4\%) were screened and determined to be ineligible. This included 288 telephone numbers not in service, 49 respondents not in the eligible age range, 234 not living in DCC, and 40 living in DCC for less than one year. In addition, 1440 respondents were excluded based on sex given the stratified sampling design. No information was obtained from 2259 (41.2\%) telephone numbers, including 1713 with no contact and 546 where the respondent declined to participate. 
Assuming the proportion of eligible individuals (36.4\%) amongst those who were contacted and screened for eligibility was the same as those unable to be contacted or who declined, 823 of these 2259 telephone numbers were estimated to be eligible. Interviews were completed with 1047 respondents out of 1999 eligible (known and estimated) telephone numbers, giving an overall response rate of $52.4 \%$. Based on all known eligible respondents contacted, the overall cooperation rate was $89.0 \%$. Table 1 presents these call outcomes and response rates overall and by mobile telephone operator. 
Table 1

Call outcome classification and response rates overall and by mobile telephone operator for the live poultry exposure mobile telephone survey, Dhaka City Corporation, Bangladesh

\begin{tabular}{|c|c|c|c|c|c|c|c|c|c|c|}
\hline & \multicolumn{2}{|l|}{ All } & \multicolumn{2}{|c|}{ Grameenphone } & \multicolumn{2}{|c|}{ Robi Axia } & \multicolumn{2}{|c|}{ Banglalink } & \multicolumn{2}{|c|}{ Teletalk } \\
\hline & $\mathbf{N}$ & $\%$ & $\mathbf{N}$ & $\%$ & $\mathbf{N}$ & $\%$ & $\mathbf{N}$ & $\%$ & $\mathbf{N}$ & $\%$ \\
\hline $\begin{array}{l}\text { Telephone } \\
\text { numbers } \\
\text { dialed }\end{array}$ & 5486 & 100.0 & 1901 & 100.0 & 2100 & 100.0 & 1346 & 100 & 139 & 100.0 \\
\hline $\begin{array}{l}\text { Total } \\
\text { ineligible: }\end{array}$ & 2051 & 37.4 & 697 & 36.7 & 932 & 44.4 & 367 & 27.3 & 55 & 39.6 \\
\hline $\begin{array}{l}\text { Not in } \\
\text { service }\end{array}$ & 288 & 5.2 & 42 & 2.2 & 115 & 5.5 & 126 & 9.4 & 5 & 3.6 \\
\hline $\begin{array}{l}<18 \text { years } \\
\text { age }\end{array}$ & 49 & 0.9 & 15 & 0.8 & 13 & 0.6 & 18 & 1.3 & 3 & 2.2 \\
\hline $\begin{array}{l}\text { Does not } \\
\text { live in DCC }\end{array}$ & 234 & 4.3 & 89 & 4.7 & 31 & 1.5 & 113 & 8.4 & 1 & 0.7 \\
\hline $\begin{array}{l}\text { Less than } 1 \\
\text { year in DCC }\end{array}$ & 40 & 0.7 & 20 & 1.1 & 5 & 0.2 & 13 & 1.0 & 2 & 1.4 \\
\hline $\begin{array}{l}\text { Not eligible } \\
\text { sex (strata } \\
\text { complete) }\end{array}$ & 1440 & 26.2 & 531 & 27.9 & 768 & 36.6 & 97 & 7.2 & 44 & 31.7 \\
\hline $\begin{array}{l}\text { Total } \\
\text { unknown } \\
\text { eligibility: }\end{array}$ & 2259 & 41.2 & 663 & 34.9 & 817 & 38.9 & 723 & 53.7 & 56 & 40.3 \\
\hline No contact & 1713 & 31.2 & 441 & 23.2 & 643 & 30.6 & 590 & 43.8 & 39 & 28.1 \\
\hline $\begin{array}{l}\text { Declined } \\
\text { (no } \\
\text { eligibility } \\
\text { screening) }\end{array}$ & 546 & 10.0 & 222 & 11.7 & 174 & 8.3 & 133 & 9.9 & 17 & 12.2 \\
\hline $\begin{array}{l}\text { Total } \\
\text { eligible } \\
\text { (known + } \\
\text { estimated): }\end{array}$ & 1999 & 100.0 & 831 & 100.0 & 575 & 100.0 & 553 & 100.0 & 47 & 100.0 \\
\hline \multicolumn{11}{|l|}{$\begin{array}{l}\text { No } \\
\text { interview: }\end{array}$} \\
\hline Refusal & 8 & 0.4 & 0 & 0.0 & 2 & 0.3 & 6 & 1.1 & 0 & 0.0 \\
\hline $\begin{array}{l}\text { Incomplete } \\
\text { or } \\
\text { terminated }\end{array}$ & 121 & 6.1 & 54 & 6.5 & 39 & 6.8 & 26 & 4.7 & 2 & 4.3 \\
\hline $\begin{array}{l}\text { No } \\
\text { information } \\
\text { (estimated } \\
\text { eligible) }{ }^{a}\end{array}$ & 823 & 41.2 & 290 & 34.9 & 224 & 38.9 & 297 & 53.7 & 19 & 40.3 \\
\hline $\begin{array}{l}\text { Complete } \\
\text { interviews } \\
\text { (response } \\
\text { rate) }\end{array}$ & 1047 & 52.4 & 487 & 58.6 & 310 & 54.0 & 224 & 40.5 & 26 & 55.4 \\
\hline
\end{tabular}




\section{All}

Grameenphone

Robi Axia

Banglalink

Teletalk

Note: DCC, Dhaka City Corporation

aEstimated eligible number calculated using AAPOR guidelines (31), assuming the proportion of eligible individuals amongst those who were contacted and screened is the same as for those who were unable to be contacted or declined.

\section{Sample Characteristics \& Representativeness}

As compared to the DCC demographic profile from the 2011 census, the unweighted mobile telephone survey sample overrepresented males aged 25-34 years as well as males and females with higher secondary education, while it underrepresented males and females aged 55-74 years and those with primary or less than primary education. Given the stratified sampling design aiming for equal representation of males and females, the overall unweighted sample overrepresented females and underrepresented males. After post-stratification weighting on these key variables, the sample matched the population closely on age, sex and education (Table 2).

Table 2

Comparison of unweighted and weighted survey sample with 2011 census population benchmarks for the live poultry exposure mobile telephone survey, Dhaka City Corporation, Bangladesh

\begin{tabular}{|c|c|c|c|c|c|c|c|c|c|}
\hline & \multicolumn{3}{|c|}{ Unweighted Sample } & \multicolumn{3}{|c|}{ Weighted Sample ${ }^{a}$} & \multicolumn{3}{|c|}{ Census Benchmarks $^{b}$} \\
\hline & $\begin{array}{l}\text { Male } \\
\text { (\%) }\end{array}$ & $\begin{array}{l}\text { Female } \\
(\%)\end{array}$ & $\begin{array}{l}\text { All } \\
(\%)\end{array}$ & $\begin{array}{l}\text { Male } \\
\text { (\%) }\end{array}$ & $\begin{array}{l}\text { Female } \\
(\%)\end{array}$ & $\begin{array}{l}\text { All } \\
(\%)\end{array}$ & $\begin{array}{l}\text { Male } \\
\text { (\%) }\end{array}$ & $\begin{array}{l}\text { Female } \\
(\%)\end{array}$ & $\begin{array}{l}\text { All } \\
(\%)\end{array}$ \\
\hline \multicolumn{10}{|l|}{ Age } \\
\hline $18-24$ & 25.4 & 26.4 & 25.9 & 25.4 & 29.3 & 27.1 & 25.4 & 29.3 & 27.1 \\
\hline $25-34$ & 40.6 & 31.0 & 35.8 & 32.7 & 32.3 & 32.5 & 32.7 & 32.3 & 32.5 \\
\hline $35-44$ & 19.0 & 23.8 & 21.4 & 20.9 & 19.7 & 20.4 & 20.9 & 19.7 & 20.4 \\
\hline $45-54$ & 9.2 & 12.8 & 11.0 & 12.1 & 11.0 & 11.6 & 12.1 & 11.0 & 11.6 \\
\hline $55-74$ & 5.8 & 5.9 & 5.9 & 8.9 & 7.7 & 8.4 & 8.9 & 7.7 & 8.4 \\
\hline \multicolumn{10}{|l|}{ Sex } \\
\hline Male & - & - & 50.0 & - & - & 57.5 & - & - & 57.5 \\
\hline Female & - & - & 50.0 & - & - & 42.5 & - & - & 42.5 \\
\hline \multicolumn{10}{|l|}{$\begin{array}{l}\text { Education (Highest } \\
\text { Completed) }\end{array}$} \\
\hline$<$ Primary & 10.0 & 10.1 & 10.1 & 20.8 & 28.1 & 23.9 & 20.8 & 28.1 & 23.9 \\
\hline Primary (year 5) & 28.8 & 24.6 & 26.7 & 30.9 & 31.4 & 31.1 & 30.9 & 31.4 & 31.1 \\
\hline Secondary (year 10) & 11.2 & 14.7 & 13.0 & 12.5 & 13.3 & 12.8 & 12.5 & 13.3 & 12.8 \\
\hline $\begin{array}{l}\text { Higher Secondary+ } \\
\text { (year 12) }\end{array}$ & 50.0 & 50.7 & 50.3 & 35.8 & 27.2 & 32.2 & 35.8 & 27.2 & 32.2 \\
\hline
\end{tabular}


The weighted survey sample is representative of other demographic factors that were not used in construction of the weights (Table 3). The overall sample shows a close match to the 2011 census figures for DCC by region, with slight discrepancies within the sex-specific strata. In terms of marital status, the survey slightly underrepresents single males and married females.

Table 3

Sample distribution compared with 2011 census population benchmarks for the live poultry exposure telephone survey, Dhaka City Corporation, Bangladesh

\begin{tabular}{|c|c|c|c|c|c|c|}
\hline & \multicolumn{3}{|c|}{ Weighted Sample ${ }^{a}$} & \multicolumn{3}{|c|}{ Census Benchmarks ${ }^{b}$} \\
\hline & Male & Female & All & Male & Female & All \\
\hline & $(\%)$ & $(\%)$ & (\%) & $(\%)$ & (\%) & (\%) \\
\hline \multicolumn{7}{|l|}{ Marital Status } \\
\hline Single, never married & 27.0 & 12.1 & 20.6 & 29.7 & 11.6 & 22.1 \\
\hline Married & 71.2 & 78.7 & 74.4 & 69.8 & 80.9 & 74.5 \\
\hline Other ${ }^{\mathrm{C}}$ & 1.8 & 9.2 & 4.9 & 0.6 & 7.4 & 3.4 \\
\hline \multicolumn{7}{|l|}{ Region } \\
\hline DCC North & 50.3 & 60.5 & 54.6 & 53.3 & 55.6 & 54.3 \\
\hline DCC South & 49.7 & 39.5 & 45.4 & 46.7 & 44.4 & 45.7 \\
\hline \multicolumn{7}{|c|}{$\begin{array}{l}\text { Note: DCC, Dhaka City Corporation } \\
\text { a Sample weighted by age, sex and education to the DCC demographic profile of the } 2011 \text { census. }{ }^{b} \text { Census data for } \\
2011 \text { DCC population, aged } 20-74 \text { for marital status and all ages for region. }{ }^{C} \text { Other includes widow/widower and } \\
\text { divorced. }\end{array}$} \\
\hline
\end{tabular}

\section{Discussion}

This study empirically examines call outcomes and sample representativeness of a probability-based mobile telephone survey sampling strategy for measuring live poultry exposure in urban Bangladesh. Our survey had an overall response rate of $52.4 \%$, and initial results comparing the socio-demographic profile of the survey sample to the census population showed that mobile telephone sampling slightly underrepresented older individuals and overrepresented those with higher secondary education. Using poststratification weighting for age, sex, and education corrected for these differences, and the weighted sample was a good match to the census on other key demographic factors. Therefore, these findings support the use of mobile telephone-based survey sampling and data collection methods for producing population representative samples with minimal adjustment, which has important implications for improving population surveillance in LMICs.

A response rate of approximately $50 \%$ is lower than previous telephone-based surveys conducted in Bangladesh (20, 32), but is in line with response rates achieved through similar methods conducted in other LMICs and is in fact higher than those typically achieved in HICs $(16,33)$. Several factors could contribute to this lower rate compared to previous work, including changes in the methods of calculating response rates over time to provide more conservative estimates and general declines in response rates of population health studies over the past 30 years $(31,34,35)$. The response rates were generally similar across mobile telephone operators, with the exception of Banglalink which was considerably lower. This could be due to differences in the geographic sampling frames between each operator, with 
Banglalink not restricted to DCC and instead sampling from telephone numbers listed in Dhaka district. Overall, this supports the use of stratified sampling designs by mobile telephone operator to appropriately capture sub-population heterogeneity when conducting population-based surveys (36).

The unweighted demographic profile of our sample differed most to the census population by educational attainment. Overrepresentation of respondents with higher education is consistent across survey research methods, including those conducted in LMICs and HICs $(14,16,37)$. The impact of these differences on population-level estimates will be greatest in surveys where education is strongly associated with the outcome of interest (38). However, the magnitude of this impact becomes negligible once weighted to the distribution of the reference population $(15,38)$. Previous research in LMICs has found that minimal adjustment of demographic factors is sufficient to reduce non-response and coverage error when conducting robust probability-based sampling (15). Additionally, comparisons with the census population show that our weighted survey achieved a good representation on other characteristics including region and marital status. Remaining differences between the census and the survey population distributions could be due to the fact that our survey sample includes only participants aged 18-74 years, whereas the published census figures include all ages for region and only ages $20-74$ years for marital status.

Although we demonstrate that population-based probability sampling using mobile telephones can produce representative samples with minimal adjustment, there are some limitations to this methodology as evidenced in this study. First, while comparisons to the census population can be used to evaluate representativeness of the sample population, it does not preclude potential for selection bias due to coverage error. For instance, those who do not have mobile telephones are likely different to those who do on the basis of factors such as socioeconomic status $(39,40)$. However, in DCC the mobile penetration rate is very high at over $87 \%$ (19), which suggests that impacts on population estimates due to coverage error are likely minimal. Further work could examine this question in populations with lower mobile telephone coverage or non-urban settings. The opposite is also of concern-potential bias introduced due to some individuals in the population having multiple mobile telephone numbers. Recent work quantifying this effect on probability of selection has found that although the theoretical probability of inclusion for those with multiple telephone numbers is greater than those with only one number, the likelihood of contacting any individual is extremely small in practice (13). Although out of the scope of our analysis, this could be examined in future work by capturing information on mobile telephone ownership and applying selection weights. Finally, poststratification survey weighting should be conducted using recent reference population estimates. However, in DCC the most recent census available is from 2011 (23), therefore any significant changes in the underlying population distribution since this time would not be reflected in the weights and could impact weighted population estimates.

\section{Conclusions}

In many LMICs, such as Bangladesh, the coverage of mobile telephones is very high and includes a range of population subgroups. Mobile telephone-based surveys can therefore offer an efficient, economic, and robust way to conduct surveillance for population health outcomes. We conducted a mobile telephone survey in Dhaka City Corporation, Bangladesh to measure live poultry exposure using a stratified probability sampling design. We evaluated the representativeness of our weighted sample population against the census and found that mobile telephone surveys can produce population representative samples with minimal adjustment in urban Bangladesh. These results have important implications for improving population health surveillance methods in LMICs. Tackling these methodological challenges is even more important in light of the COVID-19 pandemic and resultant challenges of safely conducting inperson research.

\section{Declarations}

Page $10 / 15$ 


\section{Ethics approval and consent to participate}

All study methods were carried out in accordance with relevant guidelines and regulation, and this study received ethical approval from the committees of each of the participating research institutions: University of Toronto (Protocol No. 37657), the Institute of Epidemiology Disease Control and Research (IRB/2019/11) and the London School of Hygiene and Tropical Medicine (Ref. 17661). The study was conducted in accordance with the Declaration of Helsinki. All participants provided oral informed consent via telephone.

\section{Consent for publication}

Not applicable.

\section{Availability of data and materials}

The datasets analyzed during the current study are not publicly available due to pre-existing data sharing agreements. The data may be made available from the corresponding author on reasonable request.

\section{Competing interests}

The authors declare that they have no competing interests.

\section{Funding}

IB received funding for this work through a doctoral research award from the International Development Research Center and Vanier Canada Graduate Scholarship. IB received funding for this work through an early career grant from the National Geographic Society. The funders played no role in the study design, conduct, or writing.

\section{Author Contributions}

Study conceptualization and design: IB, PM, ALG, SKM, DF, MSF; study implementation and data collection: IB, MR, IAK, $\mathrm{SS}, \mathrm{TN}$; data analysis and manuscript drafting: IB. All authors critically reviewed the manuscript for important intellectual content and approved the final version.

\section{Acknowledgements}

The authors would like to thank Dr. Khaleda Islam for feedback on the methodological implementation for this study. The authors also thank the study participants and the field teams, including data collectors at the Institute of Epidemiology, Disease Control and Research for their contributions to the study.

\section{References}

1. Corsi DJ, Neuman M, Finlay JE, Subramanian S. Demographic and health surveys: a profile. International journal of epidemiology. 2012;41(6):1602-13.

2. Luhar S, Mallinson PAC, Clarke L, Kinra S. Trends in the socioeconomic patterning of overweight/obesity in India: a repeated cross-sectional study using nationally representative data. BMJ open. 2018;8(10):e023935.

3. Jones-Smith JC, Gordon-Larsen P, Siddiqi A, Popkin BM. Cross-national comparisons of time trends in overweight inequality by socioeconomic status among women using repeated cross-sectional surveys from 37 developing countries, 1989-2007. American journal of epidemiology. 2011;173(6):667-75. 
4. Lupu N, Michelitch K. Advances in survey methods for the developing world. Annual Review of Political Science. 2018;21:195-214.

5. Dialsingh I. Face-to-Face Interviewing In: Lavrakas P, editor. Encyclopedia of Survey Research Methods. Thousand Oaks, California: Sage Publications; 2008. p. 276-61.

6. Kilmer G, Roberts H, Hughes E, Li Y, Valluru B, Fan A, et al. Surveillance of certain health behaviors and conditions among states and selected local areas; Behavioral Risk Factor Surveillance System (BRFSS), United States, 2006. 2008.

7. Iachan R, Pierannunzi C, Healey K, Greenlund KJ, Town M. National weighting of data from the behavioral risk factor surveillance system (BRFSS). BMC medical research methodology. 2016;16(1):1-12.

8. Pariyo GW, Wosu AC, Gibson DG, Labrique AB, Ali J, Hyder AA. Moving the agenda on noncommunicable diseases: policy implications of mobile phone surveys in low and middle-income countries. Journal of medical Internet research. 2017;19(5):e115.

9. Lepkowski James M. Telephone Sampling: Frames and Selection Techniques. In: Lovric M, editor. International Encyclopedia of Statistical Science. Berlin, Heidelberg: Springer Berlin Heidelberg; 2011. p. 1585-6.

10. Hu SS, Balluz L, Battaglia MP, Frankel MR. Improving public health surveillance using a dual-frame survey of landline and cell phone numbers. American journal of epidemiology. 2011;173(6):703-11.

11. Richard J-B, Andler R, Gautier A, Guignard R, Leon C, Beck F. Effects of using an overlapping dual-frame design on estimates of health behaviors: a French general population telephone survey. Journal of Survey Statistics and Methodology. 2017;5(2):254-74.

12. International Telecommunication Union. Measuring Digital Development: Facts and Figures. Geneva: ITUPublications; 2020.

13. Labrique A, Blynn E, Ahmed S, Gibson D, Pariyo G, Hyder AA. Health surveys using mobile phones in developing countries: automated active strata monitoring and other statistical considerations for improving precision and reducing biases. Journal of medical Internet research. 2017;19(5):e121.

14. Hu SS, Balluz L, Battaglia MP, Frankel MR. The impact of cell phones on public health surveillance. Bulletin of the World Health Organization. 2010;88:799-.

15. Sibai AM, Ghandour LA, Chaaban R, Mokdad AH. Potential use of telephone surveys for non-communicable disease surveillance in developing countries: evidence from a national household survey in Lebanon. BMC medical research methodology. 2016;16(1):1-8.

16. L’Engle K, Sefa E, Adimazoya EA, Yartey E, Lenzi R, Tarpo C, et al. Survey research with a random digit dial national mobile phone sample in Ghana: Methods and sample quality. PloS one. 2018;13(1):e0190902.

17. Gibson DG, Pereira A, Farrenkopf BA, Labrique AB, Pariyo GW, Hyder AA. Mobile phone surveys for collecting population-level estimates in low-and middle-income countries: a literature review. Journal of medical Internet research. 2017;19(5):e139.

18. Brinkel J, Krämer A, Krumkamp R, May J, Fobil J. Mobile phone-based mHealth approaches for public health surveillance in sub-Saharan Africa: a systematic review. International journal of environmental research and public health. 2014;11(11):11559-82.

19. Rogers M. Country overview: Bangladesh Mobile industry driving growth and enabling digital inclusion. London: GSMA Intelligence; 2018.

20. Islam K, Rahman M, Sharif A, Kawsar A, Alam Z, Rahman M, et al., editors. Introducing mobile phone for interview in surveillance system in Bangladesh: validation of the method. ASTMH; 2013; Washington, DC.

21. Lucini B, Hatt T. Country Overview: Bangladesh. GSMA Intelligence; 2014.

Page $12 / 15$ 
22. Fournié G, Høg E, Barnett T, Pfeiffer DU, Mangtani P. A systematic review and meta-analysis of practices exposing humans to avian influenza viruses, their prevalence, and rationale. The American journal of tropical medicine and hygiene. 2017;97(2):376-88.

23. Bangladesh Bureau of Statistics. Population \& Housing Census-2011: National Volume-3: Urban Area Report. Statistics and Informatics Division; 2014.

24. Bangladesh Telecommunication Regulatory Commission. The total number of Mobile Phone subscribers has reached 161.772 Million at the end of June, 20192019 [Available from: http://www.btrc.gov.bd/content/mobilephone-subscribers-bangladesh-june-2019.

25. Liao Q, Lam WT, Leung GM, Jiang C, Fielding R. Live poultry exposure, Guangzhou, China, 2006. Epidemics. 2009;1(4):207-12.

26. Liao Q, Yuan J, Lau EH, Chen GY, Yang ZC, Ma XW, et al. Live bird exposure among the general public, Guangzhou, China, May 2013. PloS one. 2015;10(12):e0143582.

27. Wang L, Cowling BJ, Wu P, Yu J, Li F, Zeng L, et al. Human exposure to live poultry and psychological and behavioral responses to influenza A (H7N9), China. Emerging infectious diseases. 2014;20(8):1296.

28. Peng Z, Wu P, Ge L, Fielding R, Cheng X, Su W, et al. Rural villagers and urban residents exposure to poultry in China. PloS one. 2014;9(4):e95430.

29. World Health Organization. Public health interventions for prevention and control of avian influenza. WHO Regional Office for South-East Asia; 2006.

30. Fitzner J, Qasmieh S, Mounts AW, Alexander B, Besselaar T, Briand S, et al. Revision of clinical case definitions: influenza-like illness and severe acute respiratory infection. Bulletin of the World Health Organization. 2018;96(2):122.

31. American Association for Public Opinion Research. Standard Definitions: Final Dispositions of Case Codes and Outcome Rates for Surveys. 9th ed: AAPOR; 2016.

32. Pariyo GW, Greenleaf AR, Gibson DG, Ali J, Selig H, Labrique AB, et al. Does mobile phone survey method matter? Reliability of computer-assisted telephone interviews and interactive voice response non-communicable diseases risk factor surveys in low and middle income countries. PLoS One. 2019;14(4):e0214450.

33. Centers for Disease Control and Prevention. Behavioral Risk Factor Surveillance System: 2018 Summary Data Quality Report. 2019.

34. Czajka JL, Beyler A. Background paper declining response rates in federal surveys: Trends and implications. Mathematica policy research. 2016;1:1-86.

35. Curtin R, Presser S, Singer E. Changes in telephone survey nonresponse over the past quarter century. Public opinion quarterly. 2005;69(1):87-98.

36. Buskirk T, Callegaro M. Cell Phone Sampling. In: Lavrakas P, editor. Encyclopedia of Survey Research Methods. Thousand Oaks, California: Sage Publications; 2008. p. 85-9.

37. Søgaard AJ, Selmer R, Bjertness E, Thelle D. The Oslo Health Study: The impact of self-selection in a large, population-based survey. International journal for equity in health. 2004;3(1):1-12.

38. Van der Heyden J, De Bacquer D, Gisle L, Demarest S, Charafeddine R, Drieskens S, et al. Additional weighting for education affects estimates from a National Health Interview Survey. The European Journal of Public Health. 2017;27(5):892-7.

39. Wesolowski A, Eagle N, Noor AM, Snow RW, Buckee CO. Heterogeneous mobile phone ownership and usage patterns in Kenya. PloS one. 2012;7(4):e35319. 
40. Ahmed T, Rizvi SJR, Rasheed S, Iqbal M, Bhuiya A, Standing H, et al. Digital Health and Inequalities in Access to Health Services in Bangladesh: Mixed Methods Study. JMIR mHealth and uHealth. 2020;8(7):e16473.

Figures

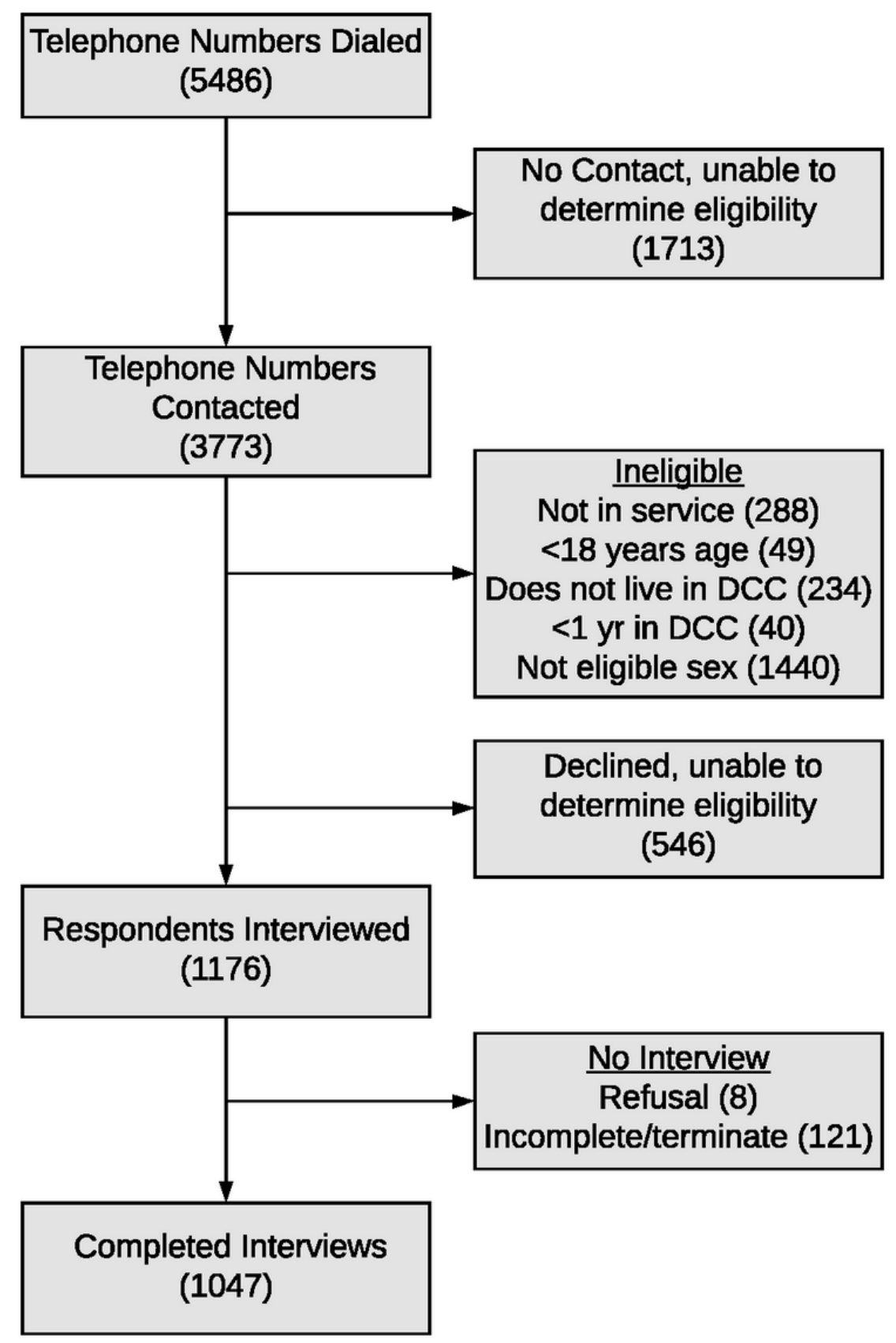

Figure 1

Profile of participant recruitment and call outcome classification for the live poultry exposure mobile telephone survey, Dhaka City Corporation, Bangladesh

\section{Supplementary Files}


This is a list of supplementary files associated with this preprint. Click to download.

- Supplementarylnformation9Feb21.docx 